\title{
Distribution of Potato virus $Y$ in Potato Plant Organs, Tissues, and Cells
}

\author{
P. Kogovšek, A. Kladnik, J. Mlakar, M. Tušek Žnidarič, M. Dermastia, M. Ravnikar, and M. Pompe-Novak
}

First, third, fourth, fifth, sixth, and seventh authors: National Institute of Biology, Department of Biotechnology and Systems Biology, Večna pot 111, 1000 Ljubljana, Slovenia; and second author: Department of Biology, Biotechnical Faculty, University of Ljubljana, Večna pot 111, 1000 Ljubljana, Slovenia.

Accepted for publication 14 June 2011.

\begin{abstract}
Kogovšek, P., Kladnik, A., Mlakar, J., Tušek Žnidarič, M., Dermastia, M., Ravnikar, M., and Pompe-Novak, M. 2011. Distribution of Potato virus $Y$ in potato plant organs, tissues, and cells. Phytopathology 101:1292-1300.

The distribution of Potato virus $Y$ (PVY) in the systemically infected potato (Solanum tuberosum) plants of the highly susceptible cultivar Igor was investigated. Virus presence and accumulation was analyzed in different plant organs and tissues using real-time polymerase chain reaction and transmission electron microscopy (TEM) negative staining methods. To get a complete insight into the location of viral RNA within

the tissue, in situ hybridization was developed and optimized for the detection of PVY RNA at the cellular level. PVY was shown to accumulate in all studied leaf and stem tissues, in shoot tips, roots, and tubers; however, the level of virus accumulation was specific for each organ or tissue. The highest amounts of viral RNA and viral particles were found in symptomatic leaves and stem. By observing cell ultrastructure with TEM, viral cytoplasmic inclusion bodies were localized in close vicinity to the epidermis and in trichomes. Our results show that viral RNA, viral particles, and cytoplasmic inclusion bodies colocalize within the same type of cells or in close vicinity.
\end{abstract}

The initial entry of viruses into plant cells occurs via physical penetration of the cell wall, for example by insects that feed on the plant or following mechanical wounding of leaf trichomes or epidermal cells (44). From the entry site the virus spreads by cellto-cell movement and then systemically through the phloem which is connected with photo assimilate transport in a source-tosink manner (37). At a later stage, when leaves become older and mature, the import of the virus and the photo assimilates stops and in the process of senescence the photo assimilates and other components are transported from old leaves to actively growing ones. In parallel with virus movement, symptom development was also shown to be dependent on the developmental stage of the leaf at the time of infection $(29,30)$. In addition, viruses can spread through the xylem, unrelated to photo assimilate transport $(12,22,39)$. During the infection process, the virus accumulates to high levels in different organs and tissues. Identification of the sites of virus accumulation would contribute to better understanding of the virus pathogenicity.

There is only limited information on the distribution of potyviruses within the whole systemically infected plant. In systemically infected apricot, Plum pox virus (PPV) was localized within the stem pith and cortex and in close vicinity to leaf veinal tissue, where an accumulation of viral RNA and viral particles was detected (22). Accumulations of various Potato virus A (PVA) isolates were analyzed in plants of wild potato and it was shown that different virus isolates accumulate at different levels in roots and systemic leaves (37). When analyzing localization of PVA proteins within the infected leaves, coat protein was immunolocalized in the vascular parenchyma cells but not in the companion cells (37). Additionally, PVA cytoplasmic inclusion protein, helper component-proteinase, proteinase, genome-linked protein, and viral RNA were found to colocalize in parenchyma

Corresponding author: P. Kogovšek; E-mail address: polona.kogovsek@nib.si

doi:10.1094/PHYTO-01-11-0020

(c) 2011 The American Phytopathological Society and mesophyll cells (38). The spread of Tobacco etch virus construct that encodes $\beta$-glucuronidase (TEV-GUS) was followed in potato leaf and trichoma cells (20).

Potato virus $Y$ (PVY), a member of the family Potyviridae, is a filamentous virus possessing single-stranded (+)RNA $(16,24)$. It is one of the most common viruses that infect a wide range of plant species, especially from the family Solanaceae, and is naturally transmitted by aphids in the nonpersistent manner (41). It can also be mechanically transmitted (24). PVY-infected plants express diverse symptoms, depending on the cultivar and virus isolate $(5,9,47)$, and symptoms also greatly differ according to primary or secondary infection. The PVY ${ }^{\mathrm{NTN}}$ isolates present one of the biggest problems for potato production out of all PVY isolates, as they have been shown to cause potato tuber necrosis ring spot disease (PTNRD) (6), apart from some other PVY isolates, e.g., PVY ${ }^{\mathrm{N}-\mathrm{Wi}}(35,45)$. PTNRD was first reported in Hungary in the 1980s (6) and by the end of the century, PTNRD was reported globally $(7,8,14,17,19,23,28,31,34,42,49)$. Besides necrosis on tubers, naturally or artificially infected potato plants of highly sensitive cultivars normally develop chlorotic and necrotic ringspots on leaves, which appear a few days following mechanical inoculation. On systemically infected leaves, wrinkles and chlorosis, leading to senescent phenotype, develop. However, plants of various cultivars, being highly susceptible, moderately susceptible, or tolerant, express different symptoms after infection with PVY ${ }^{\mathrm{NTN}}$ (32) where the severity of symptoms was shown not to correlate with the virus titer in infected potato plants following mechanical inoculation. Nevertheless, 3 weeks after inoculation the amount of virus was shown to be similar in the majority of potato plant organs of differently sensitive susceptible cultivars (32).

The accumulation and spread of PVY through the plants in potato cultivars with different sensitivity to infection was previously analyzed at the level of organs using the enzyme-linked immunosorbent assay (ELISA) method $(32,43)$. In the potato and tobacco stem tissues, $\mathrm{PVY} \mathrm{Y}^{\mathrm{O}}$ coat protein $(\mathrm{CP})$ was localized by a tissue-print in the epidermal and phloem tissue, and in tobacco 
petiole, a dense signal was observed in the epidermis, peripheral parenchyma, and in phloem tissue (26). Immunocytochemistry was used for the localization of the CP of necrotic PVY in the vascular tissue of the inoculated tobacco leaf, where it was mainly observed in the vascular parenchyma cells but not in the companion cells (13), which was also reported for PVA (37). The typical potyviral cytoplasmic inclusion bodies were detected and localized by transmission electron microscopy within the stem epidermis of the potato plant (36). All described experiments used protein detection, and observation was either performed at the level of organs or restricted only to individual organs when performed at the tissue level.

In order to gain insight into PVY distribution within the whole potato plant, methods for detection of viral RNA need to be applied and tissues from all plant organs have to be analyzed systematically. Methods based on viral RNA amplification, namely real-time polymerase chain reaction (PCR) (25), offer insight into viral genome accumulation within the plant tissues. To observe PVY RNA at the subcellular level, an in situ hybridization (ISH) method was designed and optimized for potato plant tissues. Until now, ISH was described only for two potyviruses, namely PVA (37) and PPV (22). In both cases it was demonstrated that the strength of the signal and number of leaf sections harboring virus signal depended on the virus titer (37) and that the latter could be very low and unevenly distributed (22). Therefore, we decided to use a comprehensive approach, where we first determined the tissues harboring the highest viral amount using real-time PCR and transmission electron microscopy (TEM) negative staining. Those tissues were then selected for analysis with ISH. Furthermore, the ultrastructure of tissue sections was analyzed with TEM to observe localization of viral cytoplasmic inclusion bodies within the cells and alterations of plant cell components. Results of this integrated approach, enabling localization of three essential viral components, namely assembled viral particles, viral RNA, and cytoplasmic inclusion bodies, showed that PVY spread throughout systemically infected plants; however, the distribution within the plant was uneven. Moreover, different viral components were found to co-localize within the same type of cells or in close vicinity.

\section{MATERIALS AND METHODS}

Plant material and virus inoculation. Potato (Solanum tuberosum L.) plants of highly sensitive cultivar Igor grown from node tissue culture were planted into the soil and were kept at $21 \pm 2{ }^{\circ} \mathrm{C}$ in growth chambers, with a photoperiod of $16 \mathrm{~h}$ of light and relative humidity of $70 \%$. After 4 weeks, three bottom leaves were mechanically inoculated with a sap of $\mathrm{PVY}^{\mathrm{NTN}}$-infected plants (NIB-NTN isolate, AJ585342, referred also as NTN-Slo isolate [5] causing PTNRD [27]) or a sap of healthy plants for mock-inoculation. After approximately 3 weeks postinoculation, at the time of systemic symptoms development, various parts and types of tissues and organs of the plants were dissected with a razor blade and collected separately. From each plant all available tissues and organs were sampled. Approximately one third of the plants had one small tuber. Material was divided into four groups:

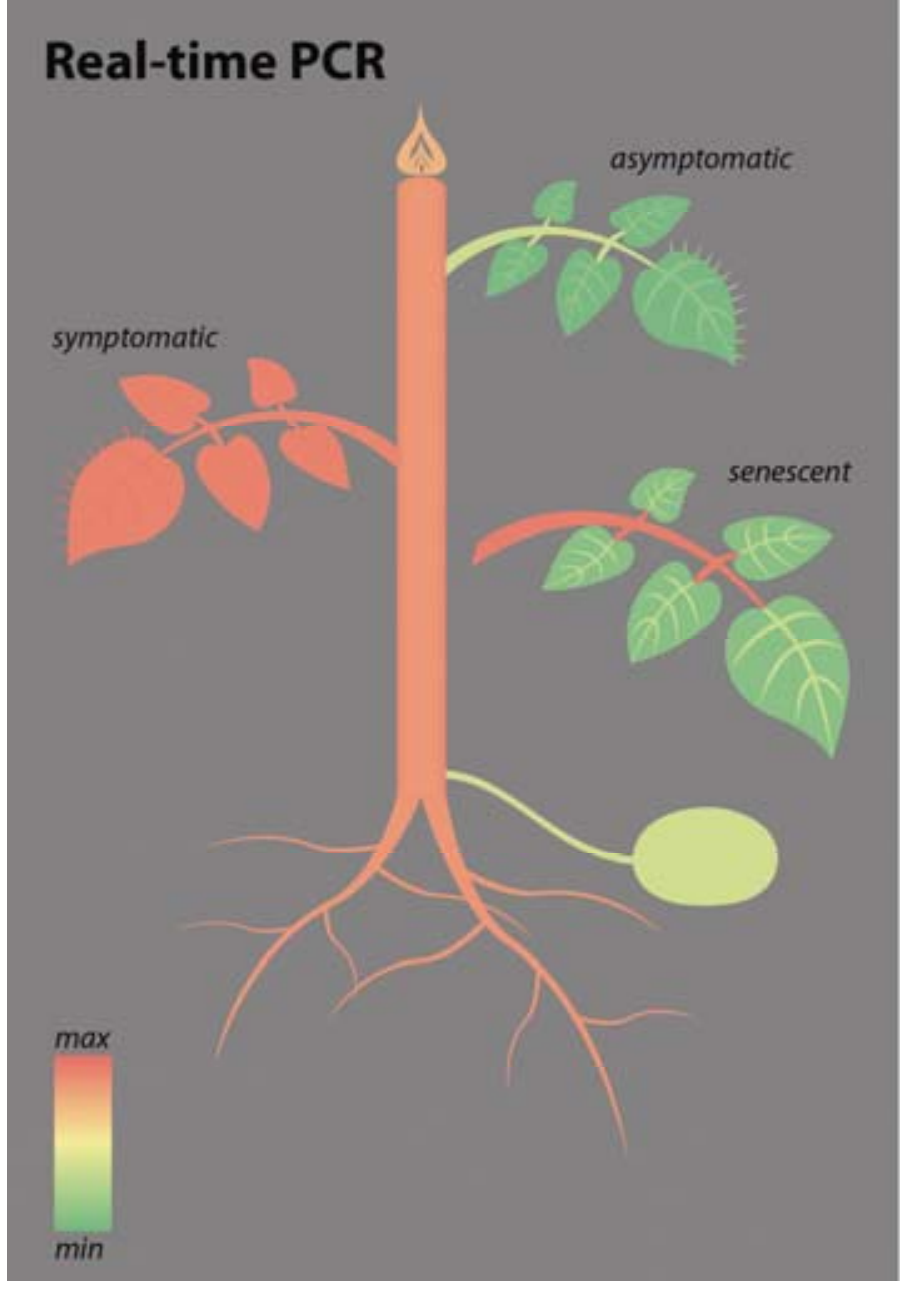

\section{TEM}

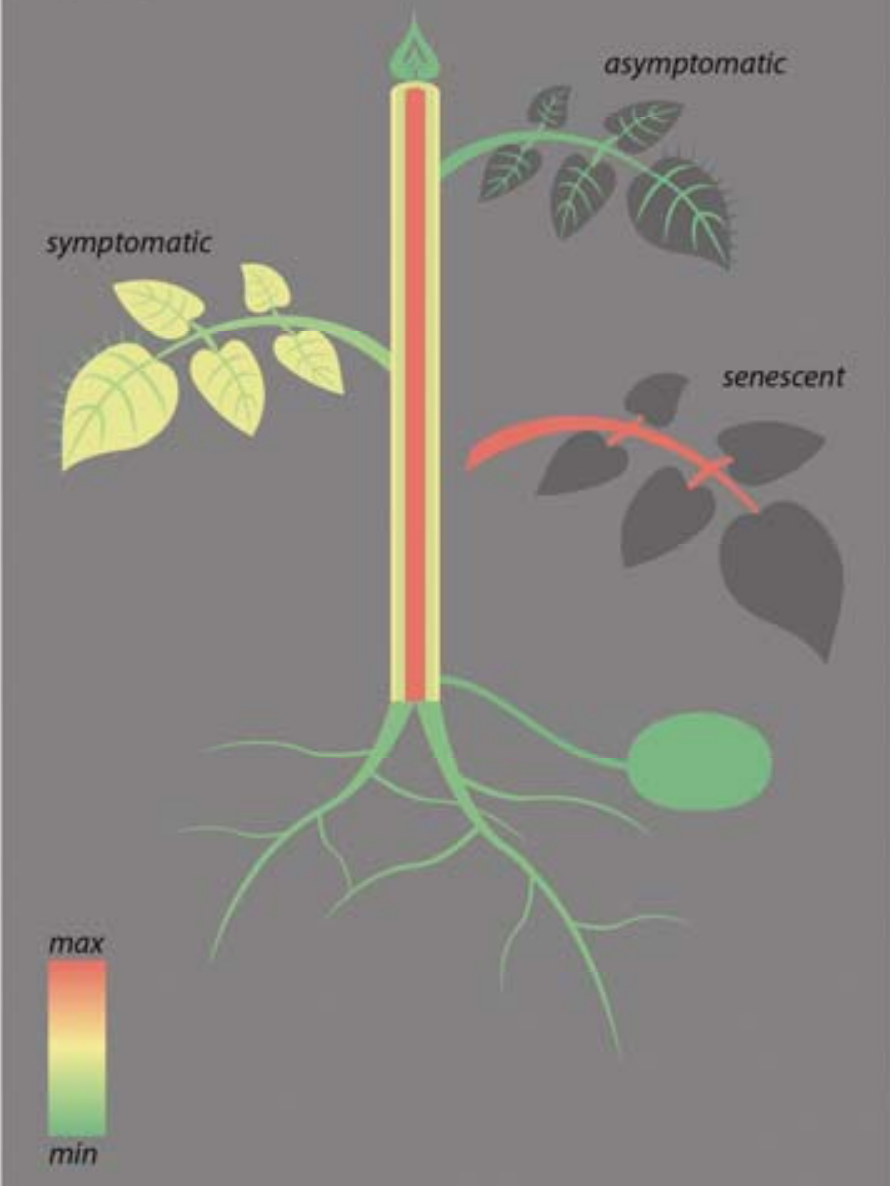

Fig. 1. Schematic presentation of the distribution of viral RNA as tested by real-time polymerase chain reaction (left) and viral particles as tested by transmission electron microscopy negative staining (right) in different plant organs and tissues. Both methods gave very similar results in which green indicates a low amount of viral RNA or particles and red indicates a high amount of viral RNA or particles. 
(i) for real-time PCR analysis, (ii) for the TEM for negative staining method, where viral particles were counted, (iii) fixing for ISH, and (iv) fixing for the observations of the ultrastructure with TEM. From the groups (i) and (ii) all the samples were further analyzed. According to the results obtained by real-time PCR and TEM negative staining method, leaf, stem and root material was further analyzed from the group (iv), and only leaf and stem material from the group (iii). The whole procedure was repeated twice, each time on three plants for each treatment for all methods.

Total RNA preparation. For a total RNA extraction, plant material was frozen and ground in liquid nitrogen and stored at $-80^{\circ} \mathrm{C}$ prior to further analysis. Total RNA was extracted from 2 to $200 \mathrm{mg}$ of plant material (depending on the amount of the material available) using the RNeasy Plant Mini kit (Qiagen, Valencia, CA) following the manufacturer's recommendations. Total RNA quality and quantity, extracted from plant material, was analyzed by an agarose gel electrophoresis and by estimating a cytochrome oxidase (COX) mRNA level by the real-time PCR assay. In order to remove remaining gDNA, DNase I (Deoxyribonuclease I, amplification grade, Invitrogen) digestion was carried out following the manufacturer's recommendations.

Real-time PCR analysis. For the detection and quantification of a PVY RNA, a single-step reverse-transcription (RT) real-time PCR assay was used (25). The samples were analyzed with specific primers and probe for the PVY ${ }^{\mathrm{NTN}}$ isolate using a Brilliant QPCR Core Reagent kit (Stratagene). Each sample was analyzed in duplicate. All real-time PCR reactions were carried out in the 384 well reaction plates using the ABI 7900HT Sequence Detection System (ABI, Foster City, CA) using real-time data collection. For amplification, standard cycling conditions were used with 30 min of preceding incubation at $48^{\circ} \mathrm{C}$ for the reverse-transcription step. For the relative viral RNA amount estimation, an antilogarithm of the subtraction between cycle threshold $(\mathrm{Ct})$ values obtained with PVY ${ }^{\mathrm{NTN}}$ amplicon and $\mathrm{Ct}$ values obtained with cytochrome oxidase (COX) amplicon was calculated. Due to the stable expression of COX observed in different plant samples $(4,21)$, the amounts of viral RNA can be compared between samples. The average of relative viral RNA amount and standard errors were calculated.

TEM. The relative amount of virus particles was examined with TEM using a negative staining method. Virus particles were extracted in an extraction buffer $(0.1 \mathrm{M}$ phosphate buffer, $\mathrm{pH} 7.2$, containing $2 \%$ polyvinylpyrrolidone) approximately in the ratio plant material: extraction buffer $=5 \mathrm{~mm}^{3}: 100 \mu \mathrm{l}$, except for the trichomes, where the ratio was lower due to the small amount of the available material. Virus particles were adsorbed on formvarcoated carbon stabilized copper grids. After $5 \mathrm{~min}$, samples were soaked away, rinsed, and stained with $1 \%$ (wt/vol) uranyl acetate. Grids were viewed with a Philips CM 100 microscope (Eindhoven, Netherlands) operating at $80 \mathrm{kV}$. Virus particles were counted under TEM in 10 randomly chosen windows on a 400 mesh grid (SPI supplies). The numbers presented are average values per 1 window at $40,000 \times$ magnification. To estimate the similarity of viral RNA and virus particle distribution the correlation coefficient was calculated.

For plant cell ultrastructure examination, parts of leaves were cut into pieces $\left(1 \mathrm{~mm}^{2}\right)$. Stems were cut to $1 \mathrm{~mm}$ long pieces. Samples were fixed in $2.5 \%$ (wt/vol) glutaraldehyde and $2 \%$ (wt/vol) paraformaldehyde in $0.1 \mathrm{M}$ phosphate buffer, postfixed in $1 \%$ osmium tetroxide, and embedded in the Agar 100 resins. Images were recorded by a Bioscan CCD camera using Digital Micrograph software, Gatan Inc. (Washington, DC). To determine the size of plasmodesmata between cells in vascular tissue, approximately 50 plasmodesmata were measured in infected and in healthy leaves.

ISH oligonucleotide probe design and optimization. Conservative sequence of the $\mathrm{CP}$ of PVY ${ }^{\mathrm{NTN}}$ (NCBI accession number AF321554) was used for the design of oligonucleotide probes with PrimerExpress (ABI, Foster City, CA). Oligonucleotide probes $4(+)$ and $4(-)$ were designed for the detection of PVYNTN $(+)$ RNA and (-)RNA, respectively (Table 1$)$. Additionally, a noncomplementary (NC) probe to either form of PVY ${ }^{\mathrm{NTN}}$ RNA with similar $\mathrm{T}_{\mathrm{m}}$ as $\mathrm{P}(+)$ and $\mathrm{P}(-)$ probes was designed to be used as a negative control. Designed probes were tested for dimmer and secondary structure formation with the program MFOLD (http:// mobyle.pasteur.fr/cgi-bin/portal.py?form=mfold).

The specificity of the probes was tested with dot blot on nylon membrane Hybond-N (Amersham Bioscience). The hybridization procedure was done as previously described (3). All probes were separately hybridized to the total RNA extracted from infected and uninfected potato plants and to water.

ISH on the fresh tissue sections. Plant tissues were hand-cut and fixed in Histochoice MB fixative (Electron Microscopy Sciences, Hatfield, PA) for $1 \mathrm{~h}$ at room temperature in $1.5-\mathrm{ml}$ tubes, followed by three washes in $1 \times$ phosphate-buffered saline (PBS). Sections were prehybridized for $1 \mathrm{~h}$ at $60^{\circ} \mathrm{C}$ in hybridization buffer (10\% dextran sulphate, $5 \times \mathrm{SSC}[1 \times \mathrm{SSC}$ is $0.15 \mathrm{M}$ $\mathrm{NaCl}$ plus $0.015 \mathrm{M}$ sodium citrate], and $0.1 \%$ Triton $\mathrm{X}-100$ in diethylprocarbonate [DEPC]-treated water). Hybridization was carried out overnight at $50^{\circ} \mathrm{C}$ with oligonucleotide probes $(0.05 \mathrm{pmol} / \mu \mathrm{l})$ (Table 1) in hybridization buffer. After hybridization, sections were washed in $1 \times$ PBS $+0.1 \%$ Triton $X-100(3 \times$ $10 \mathrm{~min}$ at room temperature), followed by the chromogenic detection using anti-digoxigenin Fab fragments conjugated with alkaline phosphatase and NBT/BCIP substrate solution. Sections were mounted in GelMount (Sigma-Aldrich, St. Louis, MO). Water insoluble violet precipitate was observed with bright-field microscopy (Axioskop 2 MOT, Carl Zeiss, Germany) and photographed with an AxioCam HRc digital camera (Carl Zeiss Vision, Germany).

\section{RESULTS}

Symptoms appearance. Five to six days after inoculation with $\mathrm{PVY}^{\mathrm{NTN}}$, typical local symptoms, expressed as chlorotic and necrotic ringspots, developed on inoculated potato leaves. Three weeks after inoculation, when inoculated leaves had already

TABLE 1. Oligonucleotide probe sequences and their length, CG content, and melting temperature $\left(\mathrm{T}_{\mathrm{m}}\right)^{\mathrm{a}}$

\begin{tabular}{|c|c|c|c|c|}
\hline Probe & Sequence $\left(5^{\prime}-3^{\prime}\right)$ & Length (bp) & $\mathrm{CG}(\%)$ & $\mathrm{T}_{\mathrm{m}}\left({ }^{\circ} \mathrm{C}\right)$ \\
\hline $\mathrm{P}(+) .1$ & ATCTCCATCCATCATAACCCAAACTCCATTGAT-DIG & 33 & 39.4 & 65.8 \\
\hline $\mathrm{P}(+) .2$ & CTCAACGATTGGTTTCAGTGGGTATTCGACTT-DIG & 32 & 43.8 & 66.9 \\
\hline $\mathrm{P}(+) .3$ & DIG-CTTCATTTGAATGTGCGCTTCCCTAGCCCTC & 31 & 51.6 & 69.5 \\
\hline $\mathrm{P}(+) .4$ & DIG-GCATTTCTATATACGCTTCTGCAACATCTGAG & 32 & 40.6 & 65.6 \\
\hline $\mathrm{P}(-) .1$ & DIG-ATCAATGGAGTTTGGGTTATGATGGATGGAGAT & 33 & 39.4 & 65.8 \\
\hline $\mathrm{P}(-) .2$ & DIG-AAGTCGAATACCCACTGAAACCAATCGTTGAG & 32 & 43.8 & 66.9 \\
\hline $\mathrm{P}(-) .3$ & GAGGGCTAGGGAAGCGCACATTCAAATGAAG-DIG & 31 & 51.6 & 69.5 \\
\hline $\mathrm{P}(-) .4$ & CTCAGATGTTGCAGAAGCGTATATAGAAATGC-DIG & 32 & 40.6 & 65.6 \\
\hline $\mathrm{NC}$ & DIG-AGCCTAACTTGCACGGCTGACATCAACACA & 30 & 50.0 & 68.1 \\
\hline
\end{tabular}

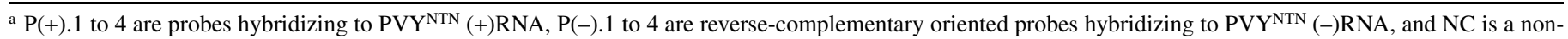
complementary probe used as a negative control. DIG indicates the position of digoxigenin label in the probe. 
fallen off, systemic symptoms developed on the majority of the upper noninoculated leaves, except on the youngest leaves (referred to as asymptomatic leaves). Systemic symptoms were expressed as chlorotic ringspots surrounded with a yellowing tissue. The chlorotic ringspots were becoming necrotic and the necrosis widened inwards resulting in the appearance of necrotic spots (referred to as symptomatic leaves). Eventually the surrounding tissue became yellow and the leaf expressed senescent-like phenotype with necrotic spots (referred to as senescent leaves). At the time of sampling, no symptoms were observed on tubers. On the control plants no changes could be observed apart from the yellowing of bottom mock-inoculated leaves.

Distribution of a viral RNA and viral particles in potato plant. All samples from PVY ${ }^{\text {NTN }}$-inoculated plants were PVY ${ }^{\text {NTN }}$ positive with real-time PCR confirming the presence of viral RNA in all tested plant tissues and organs. However, the accumulation of viral RNA varied greatly between different samples (Figs. 1 and 2). Results showed high amounts of viral RNA in shoot tip, symptomatic leaves, stem, and roots. Within the symptomatic leaves and stem, amounts of the viral RNA were high in all examined tissues. Apart from the above-mentioned organs, extremely high levels of viral RNA were also detected in petioles of the senescent leaves. In other tissues of senescent leaves and in the asymptomatic leaves considerably lower amounts of viral RNA were detected. Lower amounts of the viral RNA were also detected in tuber tissues (Figs. 1 and 2).

For all samples except trichomes, correlation coefficient 0.62 was observed between the amount of viral RNA obtained by realtime PCR and the amount of viral particles observed by TEM negative staining. The low amount of viral particles detected in trichomes of symptomatic leaves could be explained by the very low amount of trichome material available for TEM negative staining and therefore lower plant material/extraction buffer ratio used in the sample preparation procedure in comparison to other samples. Using TEM negative staining, four tissues of asymptomatic and senescent leaves of the PVY ${ }^{\mathrm{NTN}}$-inoculated plant, where low amounts of viral RNA were detected by real-time PCR, tested negative (Fig. 2), probably due to the lower sensitivity of the TEM negative staining method compared with the real-time PCR method. Similar to viral RNA, high amounts of viral particles were found in all investigated tissues of symptomatic leaves and stem, while the amount of viral particles was lower in shoot tip, asymptomatic leaves, and roots. The highest amounts of viral particles were detected in the petiole of senescent leaves and in stem pith, which was consistent with the high amounts of viral RNA in these tissues and organs (Fig. 2).

Further on, the distribution of viral RNA and viral particles were analyzed in more detail in symptomatic leaves, where regardless of tissue or organ type (lamina, vein, or trichome), we

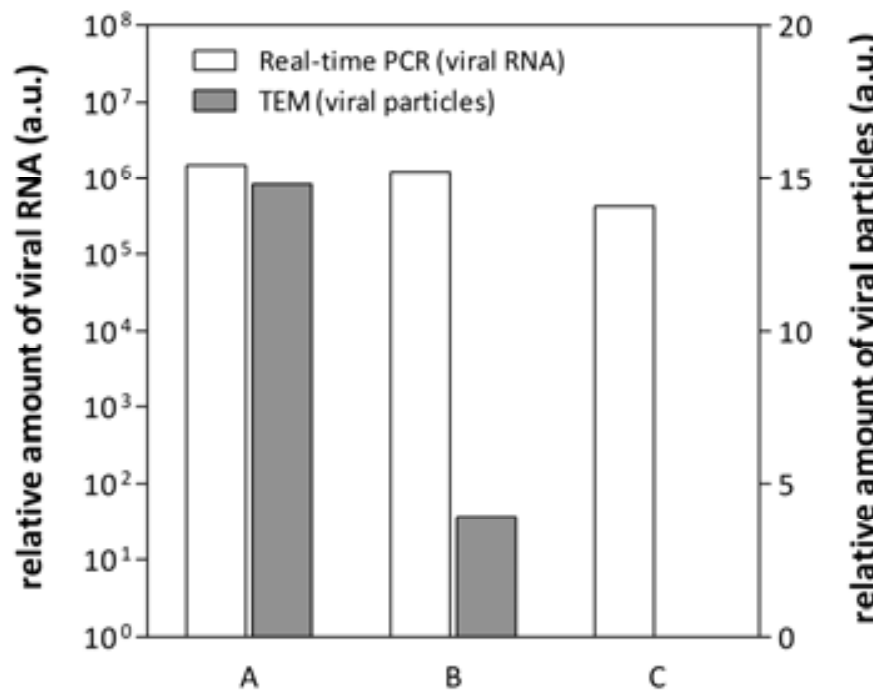

Fig. 3. Three areas of the potato leaf expressing phenotypically different symptoms were separately excised: chlorotic ringspots (A), necrotic ringspots (B), and yellowing (C). Each sample was analyzed for viral RNA (white columns) and viral particle amount (gray columns) accumulation using realtime polymerase chain reaction (PCR) and transmission electron microscopy (TEM), respectively. The primary y-axis represents relative amount of viral RNA and the secondary $y$-axis represents relative amount of viral particles.

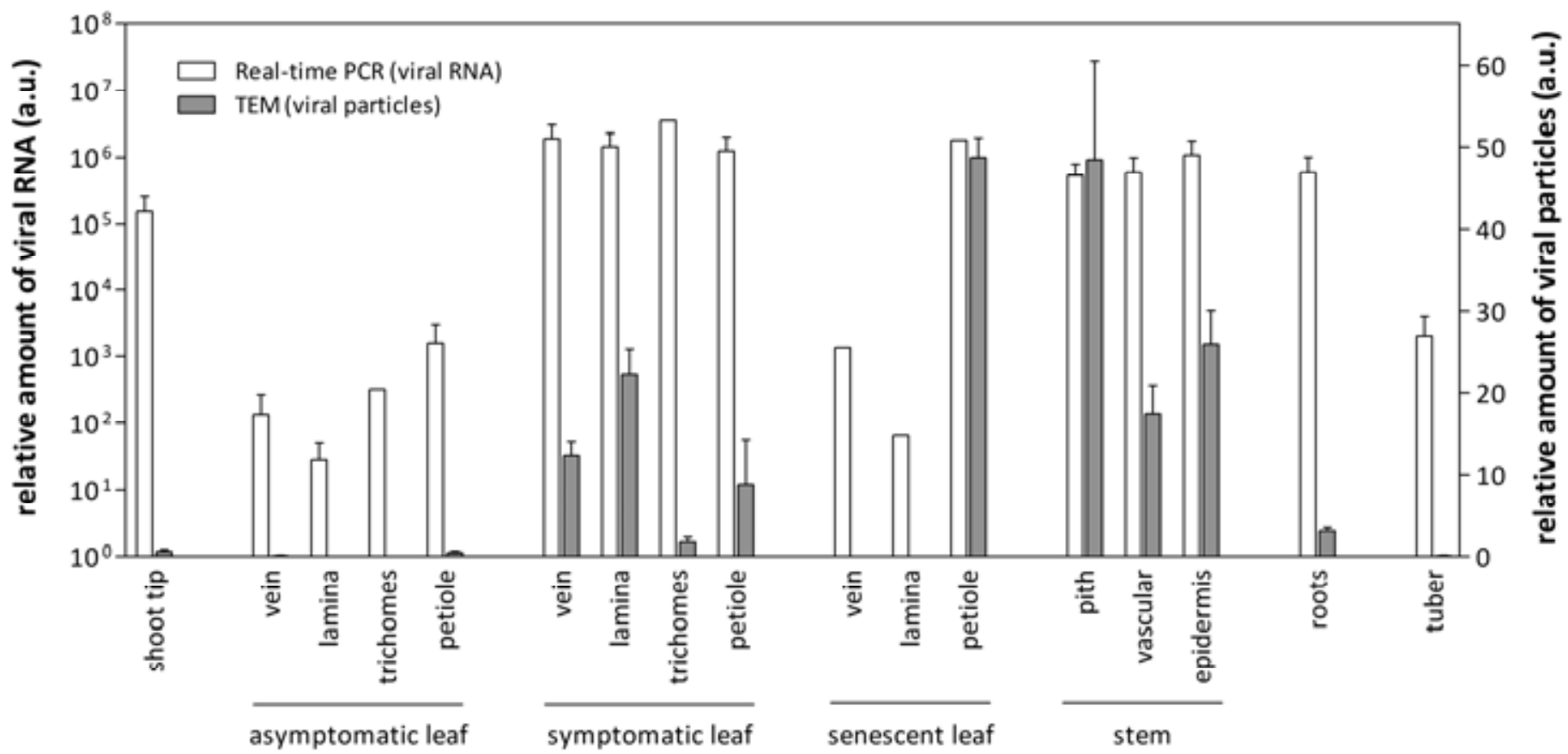

Fig. 2. Accumulation of viral RNA and viral particles in different plant organs and tissues as measured by real-time polymerase chain reaction (PCR) (white bars) and transmission electron microscopy (TEM) negative staining (gray bars), respectively. The primary y-axis represents relative amount of viral RNA determined by real-time PCR and the secondary y-axis represents relative amount of viral particles determined by TEM. No bars for TEM negative staining indicates no virus detected. 
analyzed parts of the leaves expressing visually different symptoms. We separately excised and analyzed chlorotic ringspots, necrotic ringspots, and surrounding yellowing tissue. Viral RNA was detected in all parts of the leaves, while viral particles were only detected in both types of ringspots (Fig. 3). The amount of viral particles was considerably higher in chlorotic ringspots compared with that in necrotic ringspots.

Localization of viral RNA by ISH. To proceed with the localization of viral RNA on the cellular level an ISH method for PVY $^{\text {NTN }}$ was developed. First, the specificity of the oligonucleotide probes was tested with a dot blot hybridization. A strong positive signal was obtained using all four $\mathrm{P}(+)$ probes with the total RNA extracted from infected material. However, there was no signal with RNA extracted from the healthy plant, with the exception of the probe $\mathrm{P}(+) .3$, which was accordingly omitted from further experiments. Higher melting temperature of the $\mathrm{P}(+) .3$ probe $\left(69.5^{\circ} \mathrm{C}\right.$, Table 1$)$, in comparison to other probes, could be the reason for unspecific signal with plant RNA. The NC probe designed for the negative control did not react with the total RNA extracted from the infected or healthy potato plant. The dot blot results indicated a higher amount of viral (+)RNA in the total RNA extract in comparison to (-)RNA, which presents the transcript of viral genome acting as a template for new $(+)$ RNAs. According to the dot blot results we used probe $\mathrm{P}(+) .2$ in further experiments.

In accordance with the results obtained by real-time PCR and TEM negative staining, stem, petiole, and leaf tissues were predominantly selected for the ISH analysis. In the fresh tissue sec-
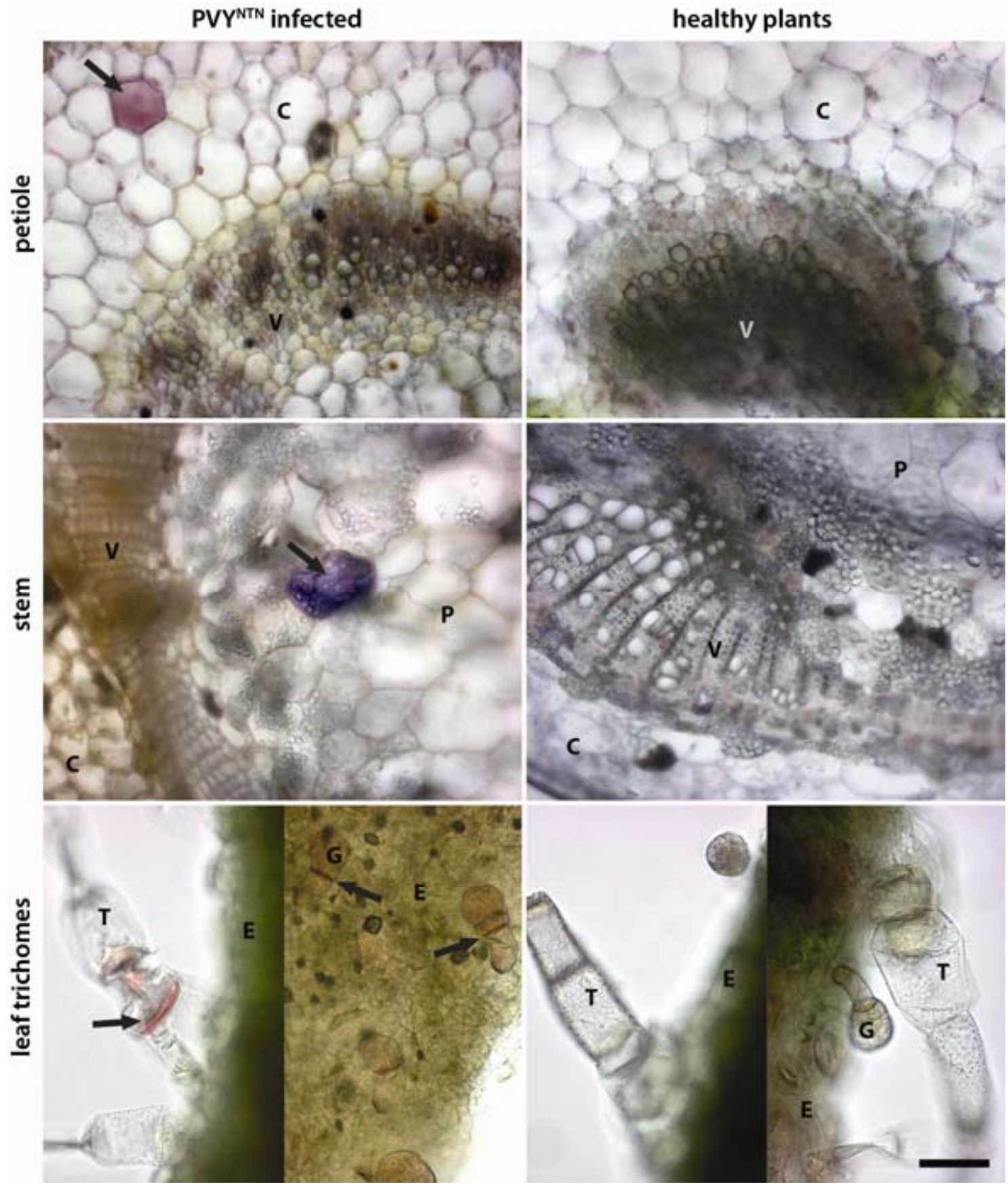

Fig. 4. Localization of the coat protein gene nucleotide sequence of Potato virus $Y$ (PVY ${ }^{\mathrm{NTN}}$ ) RNA in cells of systemically infected leaf petiole (left panel, upper figure), stem (left panel, middle figure), and leaf trichomes (left panel, lower figure) of potato cultivar Igor using in situ hybridization with a $\mathrm{P}(+) .2$ probe (purple staining). Positive signals are indicated with arrows. No signal was detected in tissues of healthy potato plants (right panel). Scale bar is $50 \mu \mathrm{m}$. C, cortex; E, epidermis; G, glandular trichomes; P, pith; T, trichomes (nonglandular); and V, vascular tissue. 
tions a specific signal was obtained in the petiole and stem tissue sections and in cells of leaf trichome of infected plants (Fig. 4). In the petiole and stem tissue sections purple staining was observed only in parenchyma cells that were located a few layers apart from vascular tissue. In the leaf lamina tissue sections no specific signal was detected but PVY ${ }^{\mathrm{NTN}}$ RNA was localized in the leaf trichome cells. Leaf trichomes contained large vacuoles that remained unstained and the specific signal was condensed in the cytoplasm. No signal was detected with the $\mathrm{P}(+) .2$ probe in uninfected tissues. In addition, the NC probe did not react positively with any tissue.

Localization of viral cytoplasmic inclusion bodies and alterations of cell components. The infected potato leaf, stem, and root tissues were observed with TEM to localize the viral cytoplasmic inclusion bodies on the subcellular level. Interestingly, cytoplasmic inclusion bodies were found in the same types of cells where viral RNA was localized with ISH. Very high amounts of the cytoplasmic inclusion bodies were detected in leaf and stem slices in parenchyma cells in close vicinity to the epidermis, in epidermal cells and in trichomes, but not in the vascular and root tip tissue. Cytoplasmic inclusion bodies were seen as pinwheels, scrolls, and laminated aggregates located in the cytoplasm (Fig. 5A and B) (46). Some cells, especially epidermal and trichome, showed accumulation of peroxisomes of different shapes and sizes located near the cytoplasmic inclusion bodies (Fig. 5C). Besides other already described ultrastructural changes, such as changes in chloroplast structure and optically dense thickenings of outer cell wall $(36,46)$, in the cells with well-

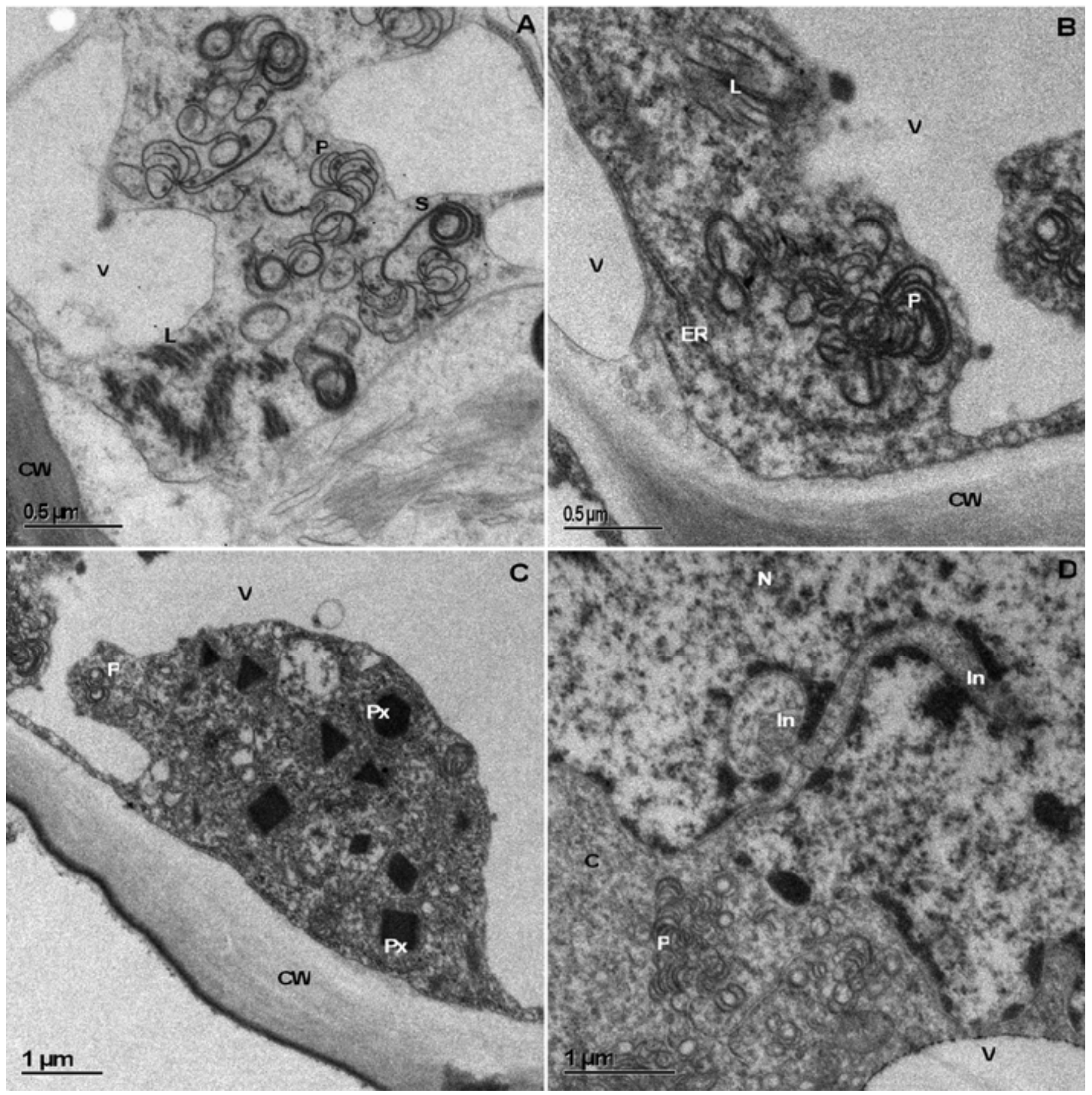

Fig. 5. Electron micrographs of cells infected with Potato virus $Y$ (PVY). A, Epidermal leaf cell with different cytoplasmic inclusion bodies. B and C, Leaf trichoma cell. D, Stem parenchyma cell with unusual nuclear invagination. CW, cell wall; V, vacuole; P, pinwheels; S, scrolls; L, laminated aggregates; ER, endoplasmic reticulum; Px, peroxisome; $\mathrm{N}$, nucleus; and $\mathrm{C}$, cytoplasm in cytoplasmic invagination. 
developed pinwheels, nuclei with unusual invaginations were found (Fig. 5D).

Although the characteristic morphology of assembled virus PVY $^{\text {NTN }}$ was not clearly distinguished, the tubular structure in aggregates with outer diameter around $20 \mathrm{~nm}$ and inner diameter from 6 to $8 \mathrm{~nm}$ and with clearly visible edge, observed in the vicinity of pinwheels might represent viral particles (Fig. 6). Tubular aggregates, cytoplasmic inclusion bodies, accumulation of peroxisomes, and nuclei with invaginations were not found in any healthy tissues. In contrast to the healthy leaf tissues, in infected leaves an increased number and size of plasmodesmata (i.e., 60 to $70 \mathrm{~nm}$ instead of usual 40 to $50 \mathrm{~nm}$ ) between cells in vascular tissue was observed (Fig. 7).

\section{DISCUSSION}

To obtain a complete picture of the distribution and accumulation of PVY in potato plants, a comprehensive approach was used that involved four different methods, each offering its own aspect of viral compound accumulation. Real-time PCR enabled the localization of viral RNA and TEM negative staining the localization of viral particles on the tissue level, newly developed ISH enabled the determination of viral RNA accumulation on the cellular level and TEM of ultrathin sections enabled the localization of viral cytoplasmic inclusion bodies on the subcellular level. Previous attempts of localizing potyviral RNA with ISH report on many constraints. The localization of PPV in apricot with ISH revealed irregular distribution and variable concentrations of the virus within tissue sections and a low sensitivity of the method leading to the absence of the signal in tissues harboring few viral RNA molecules (22). Similarly, in the wild potato plants infected with a mild PVA isolate, a smaller number of tissue sections reacted positively with ISH and the virus specific signal was weaker than in tissues infected with more aggressive virus isolates (37). To avoid the deficiency of the previous approaches, we initially determined potato tissues harboring the
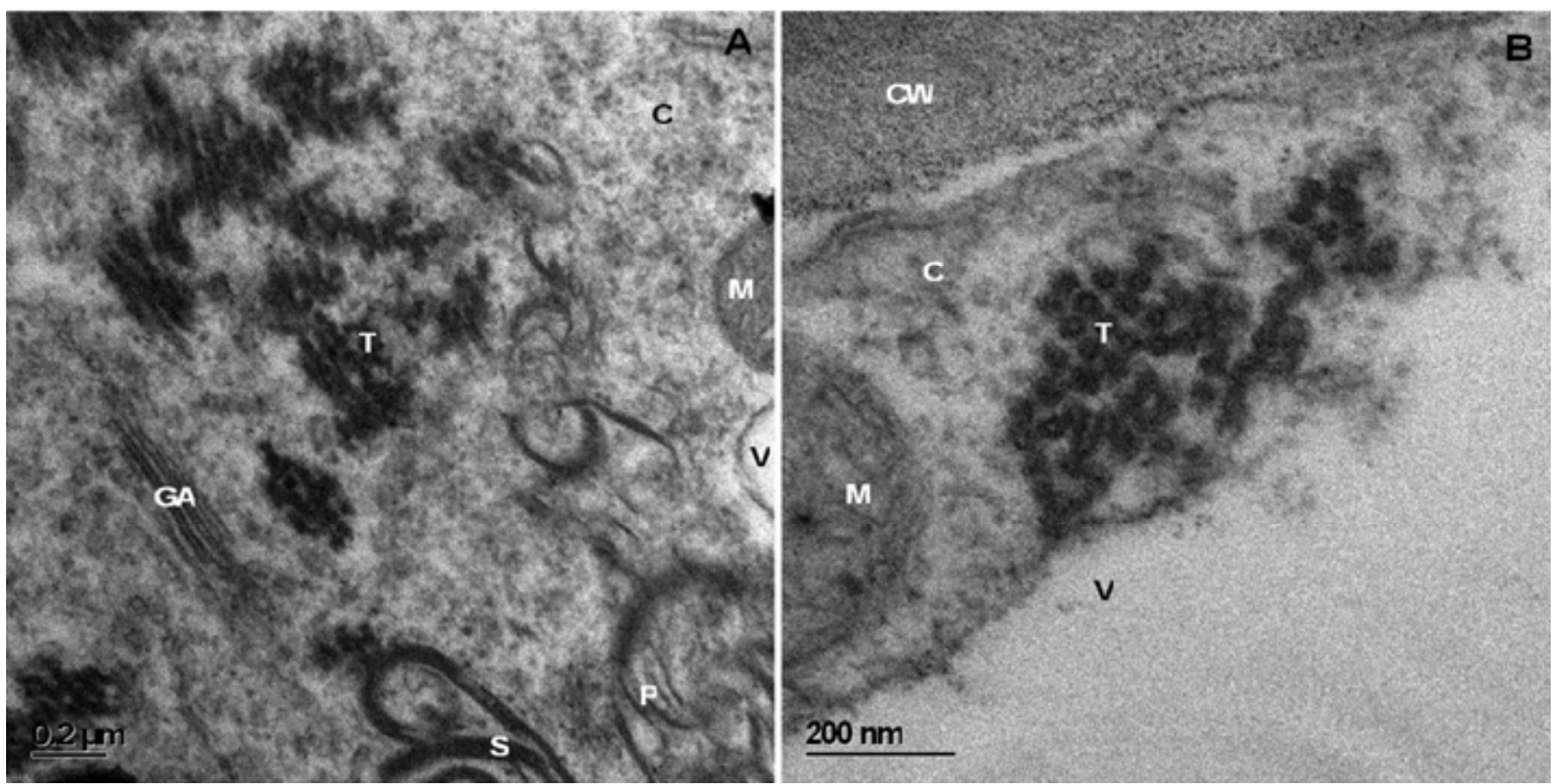

Fig. 6. Tubular aggregates accumulated in Potato virus $Y$ (PVY $\left.{ }^{\mathrm{NTN}}\right)$-infected cells in A, parenchymal and B, epidermal stem cell. C, cytoplasm; V, vacuole; GA, Golgi apparatus; P, pinwheels; S, scrolls; T, tubular structures; CW, cell wall; and M, mitochondrion.
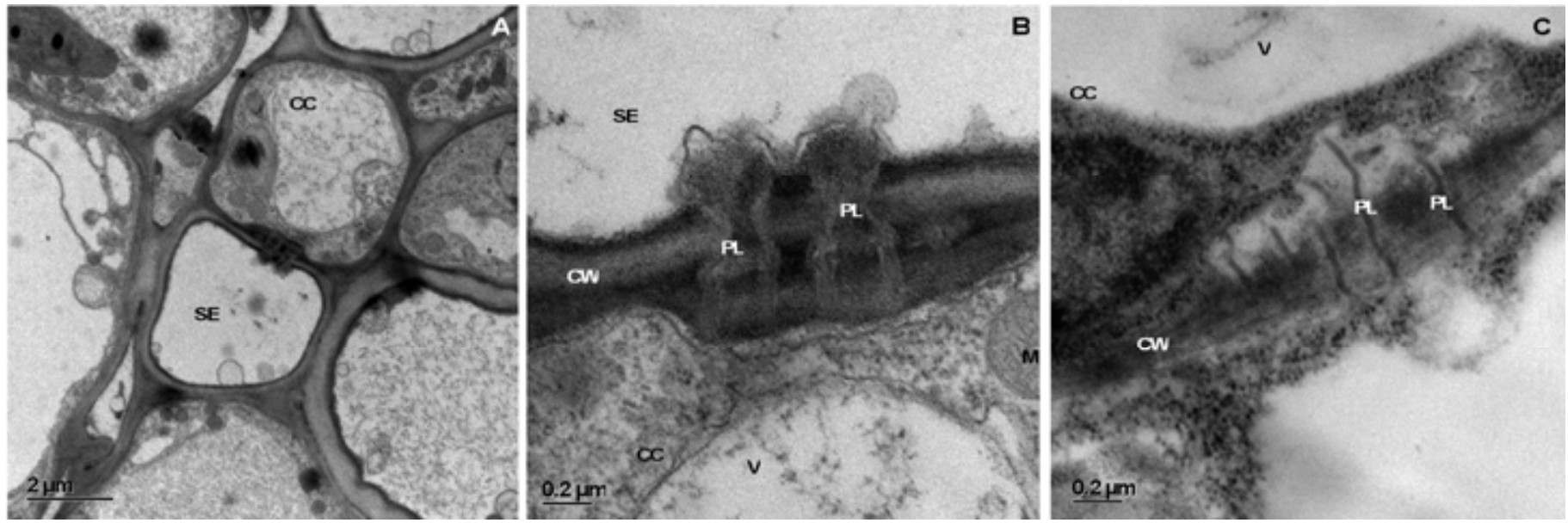

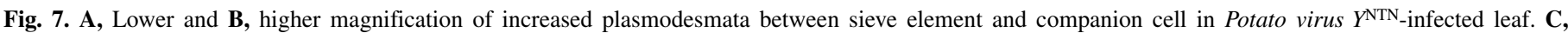

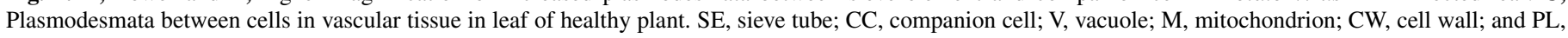
plasmodesmata. 
highest PVYNTN amounts by the real-time PCR and TEM negative staining methods and in the next stage prepared sections of those tissues for analysis with ISH and TEM.

A comparison of four different methods used to localize PVY $^{\mathrm{NTN}}$ in potato plants revealed that the ISH method is the most technically demanding. The ISH was carried out on the paraffin embedded (data not shown) and fresh tissue sections and we detected clear signals only in the case of the latter technique. Because only unspecific signals were obtained with an application of the mRNA probes (data not shown) those probes were omitted from further experiments. Instead we used only $\mathrm{P}(-)$ and $\mathrm{P}(+)$ oligonucleotide probes, which hybridize to viral $(-) \mathrm{RNA}$ and (+)RNA, respectively. ISH with $\mathrm{P}(+)$ gave distinctive signals, while $\mathrm{P}(-)$ probes gave no signal. These results were in agreement with the dot blot experiments in which $\mathrm{P}(-)$ probes gave lower signals than $\mathrm{P}(+)$ probes, indicating that smaller amounts of $(-)$ RNA PVY ${ }^{\text {NTN }}$ accumulate in the cells. Similar observations are reported in oat, in which (+) and (-)RNAs accumulated at different times after being infected with Barley yellow dwarf virus. Both RNA strands were detected early after infection but later (more than 5 days after inoculation), (+)RNA was abundant, while (-)RNA was difficult to detect (33).

Three types of leaves present on the PVY ${ }^{\mathrm{NTN}}$ systemically infected potato plants, namely asymptomatic, symptomatic, and symptomatic senescent leaves, were tested for virus accumulation. Virus distribution observed in those three types of leaves indicate that the amount of viral RNA and viral particles in the leaves changes over time and that those changes could be connected to the changes in symptom appearance or stage of the infection.

Within the symptomatic leaf, three phenotypically different tissues were analyzed, namely chlorotic and necrotic ringspots and surrounding yellowing tissue. The high amounts of viral RNA and viral particles observed within chlorotic ringspots could be connected with high rate of virus replication and assembly. The latter process could be supported by high photosynthetic capacity, which is anticipated from the higher chlorophyll content. In the necrotic ringspots viral particles might also be the subject of the degradation process, while viral RNA, which was already reported to be very stable (32), persists in necrotic tissue and also in yellowing lamina for a longer period of time.

Interestingly, low amounts of viral RNA and no particles were detected in leaf lamina and veins of senescent leaves. A similar observation was made in potato plants of susceptible cultivar, where due to senescent leaves included in the testing, lower PVY virus titer was detected (15). The phenomena could be explained by the degradation of all, plant and viral, components in order to transport them in other parts of the plant. High amounts of virus detected in the petiole, being the last link between senescent lamina and stem, in part confirms the idea.

All four techniques used for PVY ${ }^{\text {NTN }}$ localization indicated high amounts of viral RNA and viral particles accumulated in trichomes and in parenchyma cells close to epidermis. The presence of the virus in trichome cells of systemically infected leaves supports the idea of the unidirectional flow of solutes towards the trichome tip described in tobacco leaves (10) which is additionally sustained by the observation of faster Tobacco mosaic virus movement towards trichome ends in microinjected Nicotiana clevelandii leaf trichome (48). Until now, only a limited number of reports describe virus accumulation in trichomes of systemically infected leaves, namely Cucumber mosaic virus particles in cucumber leaves (40) and Potato virus $X$ (PVX) fused with gus gene (PVX.GUS) in N. clevelandii, where GUS activity was detected (1). Previous reports on virus accumulation and movement through plasmodesmata of trichome cells are based mainly on the analysis of virus microinjected $(2,11,48)$ or mechanically infected trichomes (20), where spread from trichomes to mesophyll cells was analyzed. However, the movement of the assembled virus from mesophyll cells to trichome and its accumu- lation has not yet been described. Our results show the accumulation of viral RNA, as shown by real-time PCR (Fig. 2) and ISH (Fig. 4), assembled viral particles (TEM negative staining, Fig. 2) and cytoplasmic inclusion bodies (Fig. 5B and C) in trichome cells of symptomatic leaves. Interestingly, with ISH and TEM we observed that not all trichomes possessed viral RNA or cytoplasmic inclusion bodies, respectively, but that they were rather unevenly distributed over the leaf. The latter was observed also in the case of $N$. clevelandii infected with PVX.GUS, where GUS activity spread from the injected trichome to other but not all trichome along the leaf margin (1).

In stem parenchyma cells PVY ${ }^{\text {NTN }}$ RNA and particles were detected with all techniques used. Similarly, in the same type of cells in leaves of wild potato, PVA RNA and other proteins, including cytoplasmic inclusion protein, were localized (38). Since potyviral cytoplasmic inclusion proteins are known to have an essential role in virus cell-to-cell movement (18), a high accumulation of cytoplasmic inclusion bodies could indicate the cell-to-cell movement of PVYNTN within the potato stem. The ability of the potyviruses to replicate and move from cell-to-cell through the stem parenchyma cells was already shown in apricot infected with PPV (22).

The differences observed in PVY ${ }^{\mathrm{NTN}}$ accumulation within the potato plant at early stage of systemic infection emphasize the importance of such studies. Uneven distribution of the virus indicates tissue- or organ-specific mechanisms employed by the virus or by the plant to determine the level of virus accumulation. The latter was shown to be related to symptom development. Further studies are needed to resolve if this is a general way of accumulation and distribution of all PVY strains in susceptible cultivars or a specificity of the chosen PVY ${ }^{\mathrm{NTN}}$. The next step would be the determination of virus transport and accumulation from foliage and stems to stolons and tubers, the distribution of viral compounds in tubers and the time course of viral accumulation in different parts of tubers in order to bring some new understanding on the necrosis phenomenon in tubers.

\section{LITERATURE CITED}

1. Angell, S. M., and Baulcombe, D. C. 1995. Cell-to-cell movement of Potato virus $X$ revealed by micro-injection of a viral vector tagged with the beta-glucuronidase gene. Plant J. 7:135-140.

2. Angell, S. M., Davies, C. H. R. I., and Baulcombe, D. C. 1996. Cell-tocell movement of Potato virus $X$ is associated with a change in the sizeexclusion limit of plasmodesmata in trichome cells of Nicotiana clevelandii. Virology 216:197-201.

3. Anžlovar, S., Kladnik, A., Kogovšek, P., Nikolić, P., Gruden, K., Brzin, J., and Dermastia, M. 2008. The temporal and spatial expression of pr-5 linusitin-like gene in healthy and ethylene-treated flax plants. Int. J. Plant Sci. 169:701-707.

4. Baebler, Š., Krečičc-Stres, H., Rotter, A., Kogovšek, P., Cankar, K., Kok, E. J., Gruden, K., Kovač, M., Žel, J., Pompe-Novak, M., and Ravnikar, M. 2009. PVY ${ }^{\mathrm{NTN}}$ elicits a diverse gene expression response in different potato genotypes in the first $12 \mathrm{~h}$ after inoculation. Mol. Plant Pathol. 10:263-275.

5. Barker, H., McGeachy, K., Toplak, N., Gruden, K., Žel, J., and Browning, I. 2009. Comparison of genome sequence of PVY isolates with biological properties. Am. J. Potato Res. 86:227-238.

6. Beczner, L., Horvath, J., Romhanyi, I., and Forster, H. 1984. Studies on the etiology of tuber necrotic ringspot disease in potato. Potato Res. 27:339-352.

7. Blanco-Urgoiti, B., Tribodet, M., Leclere, S., Ponz, F., Pérez de san román, C., Legorburu, F. J., and Kerlan, C. 1998. Characterization of potato potyvirus Y (PVY) isolates from seed potato batches. Situation of the NTN, Wilga and Z isolates. Eur. J. Plant Pathol. 104:811-819.

8. Buturovic, D., and Kus, M. 1989. The occurrence of potato tuber ring necrotic disease in Yugoslavia. Proc. 7th EAPR Virology Section Meeting. European Association for Potato Research, Dordrecht, The Netherlands.

9. Chikh Ali, M., Maoka, T., Natsuaki, T., and Natsuaki, K. T. 2010. PVY $^{\mathrm{NTN}-\mathrm{NW}}$, a novel recombinant strain of Potato virus $Y$ predominating in potato fields in Syria. Plant Pathol. 59:31-41.

10. Christensen, N. M., Faulkner, C., and Oparka, K. 2009. Evidence for unidirectional flow through plasmodesmata. Plant Physiol. 150:96-104. 
11. Derrick, P. M., Barker, H., and Oparka, K. J. 1992. Increase in plasmodesmatal permeability during cell-to-cell spread of Tobacco rattle virus from individually inoculated cells. Plant Cell 4:1405-1412.

12. Dicenta, F., Martinez-Gomez, P., Rubio, M., and Audergon, J. M. 2003. Localisation and movement of Plum pox virus in apricot stem tissues. Ann. Appl. Biol. 142:99-105.

13. Ding, X. S., Carter, S. A., Deom, M. C., and Nelson, R. S. 1998. Tobamovirus and potyvirus accumulation in minor veins of inoculated leaves from representatives of the Solanaceae and Fabaceae. Plant Physiol. 116:125-136.

14. Djilani-Khouadja, F., Glais, L., Tribodet, M., Kerlan, C., and Fakhfakh, H. 2010. Incidence of potato viruses and characterisation of Potato virus $Y$ variability in late season planted potato crops in Northern Tunisia. Eur. J. Plant Pathol. 126:479-488.

15. Draper, M. D., Pasche, J. S., and Gudmestad, N. C. 2002. Factors influencing PVY development and disease expression in three potato cultivars. Am. J. Potato Res. 79:155-165.

16. Fauquet, C. M., Mayo, M. A., Maniloff, J., Desselberger, U., and Ball, L. A. (eds.) 2005. Virus Taxonomy. Eight Report of the ICTV. Elsevier/ Academic Press, London.

17. Fletcher, J. D., Dannock, J., Boonham, N., Elliot, D., and Herrera, V. 2001. Potato tuber necrosis ring-spot disease (PTNRD) in New Zealand. Proc. 13th Biennial Conference of Australasian Plant Pathology Society. Australasian Plant Pathology Society, Queensland, Australia.

18. Gomez de Cedron, M., Osaba, L., Lopez, L., and Garcia, J. A. 2006. Genetic analysis of the function of the Plum pox virus CI RNA helicase in virus movement. Virus Res. 116:136-145.

19. Gray, S., De Boer, S., Lorenzen, J., Karasev, A., Whitworth, J., Nolte, P., Singh, R., Boucher, A., and Xu, H. 2010. Potato virus Y: An evolving concern for potato crops in the United States and Canada. Plant Dis. 94:1384-1397.

20. Hinrichs, J., Berger, S., and Shaw, J. G. 1998. A hypersensitive responselike mechanism is involved in resistance of potato plants bearing the Ry(sto) gene to the potyviruses Potato virus $Y$ and Tobacco etch virus. J. Gen. Virol. 79:167-176.

21. Hren, M., Nikolić, P., Rotter, A., Blejec, A., Terrier, N., Ravnikar, M., Dermastia, M., and Gruden, K. 2009. 'Bois noir' phytoplasma induces significant reprogramming of the leaf transcriptome in the field grown grapevine. BMC Genomics 10. Online http://www.biomedcentral.com/ 1471-2164/10/460.

22. Ion-Nagy, L., Lansac, M., Eyquard, J. P., Salvador, B., Garcia J. A., Le Gall, O., Hernould, M., Schurdi-Levraud, V., and Decroocq, V. 2006. PPV long-distance movement is occasionally permitted in resistant apricot hosts. Virus Res. 120:70-78.

23. Karasev, A. V., Meacham, T., Hu, X., Whitworth, J., Gray, S. M., Olsen, N., and Nolte, P. 2008. Identification of Potato virus $Y$ strains associated with tuber damage during a recent virus outbreak in potato in Idaho. Plant Dis. 92:1371-1371.

24. Kerlan, C. 2006. Potato virus Y: Descriptions of Plant Viruses. No. 414. Association of Applied Biologists, Kew, England.

25. Kogovšek, P., Gow, L., Pompe-Novak, M., Gruden, K., Foster, G. D., Boonham, N., and Ravnikar, M. 2008. Single-step RT real-time PCR for sensitive detection and discrimination of Potato virus $Y$ isolates. J. Virol. Methods 149:1-11.

26. Krzymowska, M., and Hennig, J. 1997. Simple and rapid technique to detect PVY presence in some Solanaceae plants. Acta Physiol. Plant. 19:95-99.

27. Kus, M. 1995. Investigations of the sensitivity of potato cultivars to tuber necrotic ringspot strain of potato virus Y (PVYNTN). Pages 135-138 in: Proc. 9th EAPR Virology Section Meeting. European Association for Potato Research, Dordrecht, The Netherlands.

28. Le Romancer M., Kerlan, C., and Nedellec, M. 1994. Biological characterisation of various geographical isolates of potato virus $\mathrm{Y}$ inducing superficial necrosis on potato tubers. Plant Pathol. 43:138-144.

29. Leisner, S. M., Turgeon, R., and Howell, S. H. 1992. Long distance movement of Cauliflower mosaic virus in infected turnip plants. Mol. Plant-Microbe Interact. 5:41-47.

30. Mas, P., and Pallas, V. 1996. Long-distance movement of cherry leaf roll virus in infected tobacco plants. J. Gen. Virol. 77:531-540.

31. McDonald, J. G., and Singh, R. P. 1996. Response of potato cultivars to North-American isolates of PVYNTN . Am. Potato J. 73:317-323.

32. Mehle, N., Kovač, M., Petrovič, N., Novak Pompe, M., Baebler, Š., Krečič-Stres, H., Gruden, K., and Ravnikar, M. 2004. Spread of potato virus $\mathrm{Y}^{\mathrm{NTN}}$ in potato cultivars (Solanum tuberosum L.) with different levels of sensitivity. Physiol. Mol. Plant Pathol. 64:293-300.

33. Nass, P. H., Domier, L. L., Jakstys, B. P., and D’Arcy, C. J. 1998. In situ localization of Barley yellow dwarf virus-PAV 17-kDa protein and nucleic acids in oats. Phytopathology 88:1031-1039.

34. Ohshima, K., Sako, K., Nakagawa, A., Matsuo, K., Ogawa, T., Shikata, E., and Sako, N. 2000. Potato tuber necrotic ringspot disease occurring in Japan: Its association with Potato virus $Y$ necrotic strain. Plant Dis. 84:1109-1115

35. Piche, L. M., Singh, R. P., Nie, X., and Gudmestad, N. C. 2004. Diversity among Potato virus $Y$ isolates obtained from potatoes grown in the United States. Phytopathology 94:1368-1375.

36. Pompe-Novak, M., Wrischer, M., and Ravnikar, M. 2001. Ultrastructure of chloroplasts in leaves of potato plants infected by Potato virus $Y^{\mathrm{NTN}}$. Phyton 41:215-226.

37. Rajamaki, M. L., and Valkonen, J. P. T. 2002. Viral genome-linked protein (vpg) controls accumulation and phloem-loading of a potyvirus in inoculated potato leaves. Mol. Plant-Microbe Interact. 15:138-149.

38. Rajamaki, M. L., and Valkonen, J. P. T. 2003. Localization of a potyvirus and the viral genome-linked protein in wild potato leaves at an early stage of systemic infection. Mol. Plant-Microbe Interact. 16:25-34.

39. Rasheed, M., Selth, L., Koltunow, A., Randles, J., and Rezaian, M. A. 2006. Single-stranded DNA of Tomato leaf curl virus accumulates in the cytoplasm of phloem cells. Virology 348:120-132.

40. Riedle, M. 1995. Localization of cucumber mosaic cucumovirus in infected cucumber plants by whole leaf press blotting. Pages 162-167 in: Proc. 8th Conference on Virus Diseases of Vegetables, Prague, Czech Republic.

41. Robert, Y., Woodford, J. A. T., and Ducray-Bourdin, D. G. 2000. Some epidemiological approaches to the control of aphid-borne virus diseases in seed potato crops in northern Europe. Virus Res. 71:33-47.

42. Rosner, A., and Maslenin, L. 1999. Differentiating PVYNTN by unique single-restriction cleavage of PCR products. Potato Res. 42:215-221.

43. Rusetsky, N. V., and Blotskaya, Z. V. 2001. Distribution and accumulation of PVM and PVY, PVX in infected potato plants. Arch. Phytopathol. Plant Prot. 34:275-282.

44. Scholthof, H. B. 2005. Plant virus transport: Motions of functional equivalence. Trends Plant Sci. 10:376-382.

45. Schubert, J., Fomitcheva, V., and Sztangret-Wisniewska, J. 2007. Differentiation of Potato virus $Y$ strains using improved sets of diagnostic PCR-primers. J. Virol. Methods 140:66-74.

46. Shand, K., Theodoropoulos, C., Stenzel, D., Dale, J. L., and Harrison, M. D. 2009. Expression of Potato virus Y cytoplasmic inclusion protein in tobacco results in disorganization of parenchyma cells, distortion of epidermal cells, and induces mitochondrial and chloroplast abnormalities, formation of membrane whorls and atypical lipid accumulation. Micron 40:730-736.

47. Singh, R. P., Valkonen, J. P. T., Gray, S. M., Boonham, N., Jones, R. A. C., Kerlan, C., and Schubert, J. 2008. Discussion paper: The naming of Potato virus $Y$ strains infecting potato. Arch. Virol. 153:1-13.

48. Waigmann, E., and Zambryski, P. 1995. Tobacco mosaic virus movement protein-mediated protein transport between trichome cells. Plant Cell 7:2069-2079.

49. Weidemann, H. L., and Mais, E. 1996. Detection of the potato tuber necrotic ringspot strain of Potato virus $Y$ (PVYNTN) by reverse transcription and immunocapture polymerase chain reaction. J. Plant Dis. Prot. 103:337-345. 